\title{
Gas exchange and water relations of Lemmon's willow and Nebraska sedge
}

\author{
TONY J. SVEJCAR AND JAMES D. TRENT
}

\begin{abstract}
Authors are supervisory range scientist, USDA-ARS, Eastern Oregon Agricultural Research Center, HC 714.51 Hwy 205, Burns 97720; and agricultural research technician, USDA-ARS, 920 Valley Rd, Reno, Nev. 89512. At the time of the
\end{abstract} study, the senior author was a range scientist, USDA-ARS, Reno, Nev.

\begin{abstract}
There is considerable interest in riparian zones in the western United States, yet little information is available on the autecology of plant species that dominate these areas. We measured gas exchange and xylem water potential of Nebraska sedge (Carex nebrascensis Dewey) and Lemmon's willow (Salix lemonii Bebb) growing in a streamside location in the northern Sierra Nevada over a 2 year period. Standing biomass of both species and leaf area index of Lemmon's willow was also determined. Rooting activity of Nebraska sedge was measured the second year of the study. Measurements were taken during 1988 and 1989 with growing season precipitation $46 \%$ and $110 \%$ of average, respectively. Photosynthesis was remarkably similar for the 2 species (10.9 and $11.1 \mu$ moles $^{-2}$ second $^{-1}$ for Nebraska sedge and Lemmon's willow, respectively) when averaged over all dates for the 2 years. However, the 2 species exhibited different seasonal and yearly patterns of photosynthesis. Nebraska sedge maintained higher rates of photosynthesis during the early portion of the growing season and Lemmon's willow had higher photosynthesis during mid to late summer. Mean seasonal rates of willow photosynthesis were higher than those of the sedge during the drought year, and the opposite was true during the average year. Yearly average photosynthesis varied more for the sedge than for the willow. However, mean seasonal photosynthesis rates for each species were higher in an average year compared to a drought year. Nebraska sedge almost always had more negative values of xylem water potential than Lemmon's willow (overall average was -2.6 MPa and -1.25 MPa for Nebraska sedge and Lemmon's willow, respectively). Trends in transpiration and conductance were similar among species, except that Nebraska sedge maintained higher rates than Lemmon's willow during the spring of 1989. Willow biomass was similar among years, but willow leaf area index and sedge biomass were slightly greater in the wet year (1989) compared to the dry year. Contrasting growth forms and morphology of the $\mathbf{2}$ species may help explain differences in gas exchange and xylem water potential. The ability of willows to tap groundwater and the concentration of sedge roots in the upper soil profile probably accounts for the differential response to drought.
\end{abstract}

The authors thank Scott Conroy for assistance in site selection, and USDAForest Service, Plumas National Forest for use of the site. Drs. Edith Allan, Gregg Riegel, and Joe Trlica provided constructive comments on an earlier version of the manuscript.

Manuscript accepted 7 Aug. 1994.
Key words: water stress, photosynthesis, riparian species

Riparian zones have become a focal point in the management of rangelands. Information on classification and management responses of riparian ecosystems is beginning to accumulate. However, we know relatively little about physiological responses of riparian species, or the processes that control productivity and integrity of these ecosystems.

Willows (Salix spp.) and sedges (Carex spp.) are 2 of the most important genera in riparian communities in the western United States (Youngblood et al. 1985, Kovalchik 1987). These genera exist as co-dominants in many of the more mesic riparian communities. Previous research has demonstrated that Carex-dominated communities can have very high levels of root mass and root length densities, although the vast majority of roots are concentrated in the upper 20 or $30 \mathrm{~cm}$ of soil (Manning et al. 1989). The concentration of roots in the upper soil profile is typical of the fibrous rooted graminoids. Woody plants, such as Salix spp., generally are able to extend roots deeper into the soil, although we are not aware of any detailed information on Salix rooting patterns. A study which employed stable isotopes of water demonstrated that Salix depends heavily on groundwater (Busch et al. 1992).

If Salix and Carex occupy different below-ground niches, we predict that the patterns of gas exchange (transpiration and photosynthesis) and moisture stress (xylem potential) would also differ. Presumably, the shallower-rooted Carex plants will experience water-stress and limit gas exchange earlier in the growing season than the deeper-rooted Salix. The objective of this study was to compare seasonal patterns of gas exchange and moisture stress in Lemmon's willow (Salix lemmonii Bebb) and Nebraska sedge (Carex nebrascensis Dewey) growing together on a montane streamside site.

\section{Materials and Methods}

\section{Study Area}

The study was conducted during 1988 and 1989 on Freeman Creek in the northern Sierra Nevada near Davis Lake in Plumas County, Calif. The elevation is about $1,750 \mathrm{~m}$ and precipitation averages $96 \mathrm{~cm}$ with $85 \%$ occurring between October and April. Growing season precipitation measured about $10 \mathrm{~km}$ from the study site was $46 \%$ and $110 \%$ of average during 1988 and 1989 , respectively. Downcutting had lowered the streambottom of 
Freeman Creek to about $1.5 \mathrm{~m}$ below the stream terrace and the streambank-to-streambank cross-sectional width ranged from about 6 to $10 \mathrm{~m}$. The woody vegetation was dominated by Lemmon's willow and herbaceous vegetation by Nebraska sedge. Other conspicuous species include Baltic rush (Juncus balticus Willd.) tufted hairgrass (Deschampsia cespitosa (L.) Beauv.), Beckwith clover (Trifolium beckwithii S. Watson), and lodgepole pine (Pinus contorta Loudon ssp. murrayana (Grev. and Balf.) Critchf). Nomenclature follows Hickman (1993).

\section{Gas Exchange and Xylem Water Potential}

Photosynthesis, transpiration, leaf temperature, and stomatal conductance were measured with an LI-6200 portable photosynthesis system (LI-COR, Inc., Lincoln, Neb.) ${ }^{1}$ equipped with $0.25-$ $L$ leaf chamber. Immediately after the gas exchange measurements, the leaves were excised and placed in a pressure chamber (3000 Series, Soil-Moisture Equip. Corp., Santa Barbara, Calif.) to determine xylem water potential. Leaves were placed on moist paper towels and returned to the laboratory for measurement of leaf area with a LI-3000 area meter (LI-COR, Inc, Lincoln, Neb.).

Sampling of leaves was conducted in 6 contiguous $3 \times 3 \mathrm{~m}$ blocks. Each block contained both species. In each block, 1 set of measurements was taken on fully developed leaves of Nebraska sedge and Lemmon's willow during early afternoon. Plants within each block were selected at random. We used contiguous blocks on a stretch of stream to limit the environmental variation during the measurement period. A complete set of measurements could be taken in a 2 to 3 hour period. We measured leaves exposed to full sunlight; in the case of the willows, the leaves were in the upper $1 / 3$ of the canopy and near the end of the branches. Mature willows with heights ranging from 1.5 to $2 \mathrm{~m}$ were sampled. Measurements were taken on 12 dates during late May to late September, 1988; and 13 dates during mid-April to late September, 1989.

\section{Plant Standing Crop and Soil Parameters}

Biomass of willows and sedges was determined in early September of both years. One $33.5 \times 33.5 \mathrm{~cm}$ plot per block was clipped for Nebraska sedge standing crop. Nebraska sedge made up nearly $100 \%$ of the herbaceous standing crop within the sampling locations. Three branches of Lemmon's willow per block were cut at ground level and transported to the laboratory. A subsample of leaves was scanned for area with a LI-3000 area meter (LI-COR, Lincoln, Neb.), dried at $60^{\circ} \mathrm{C}$ for 96 hours and weighed. The remaining leaves were separated from the branches. Leaf and branch material were dried at $60^{\circ} \mathrm{C}$ for a week and weighed. Leaf mass, specific leaf area, and average canopy diameter were used to calculate leaf area index of the willows. The leaf area index calculation for willow is leaf area per unit of canopy area; thus, values are not representative of willow leaf area indexes in the community as a whole, rather they represent leaf area index above the ground area occupied by willow canopies. The number of nodes with green leaves remaining on lateral branches in early and late September was determined as an index of leaf senescence.

Rooting activity was assessed using Pyrex ${ }^{\circledR}$ minirhizotron tubes in conjunction with a root periscope. The procedure and equipment used was similar to that described by Karl and

'Mention of tradename does not indicate endorsement by USDA.
Doescher (1991), except that minirhizotron tubes were inserted $30^{\circ}$ from vertical, and the bottom was sealed with a rubber stopper and epoxy. Bands of $2 \mathrm{~cm}$ width were marked on the tubes at $10 \mathrm{~cm}$ intervals. The center of the bands were at $5,15,25,35,45$, 55 , and $65 \mathrm{~cm}$ from the soil surface. Total number of root intersections in the $2 \mathrm{~cm}$ bands were counted and values are presented as root number $\mathrm{cm}^{-2}$. These values provide an index of rooting activity. Three tubes were buried along the sampling transect during September 1988 in areas dominated by sedge and measurements taken on 5 dates during 1989.

Soil temperature $(0-12 \mathrm{~cm})$ was recorded at 3 locations during each measurement date with an integrating temperature probe. Pairs of gypsum blocks (Beckman Corp. Palo Alto, Calif.) were buried at 10 and $40 \mathrm{~cm}$ soil depths at 3 locations along the sampling transect to assess soil moisture.

\section{Experimental Design and Data Analysis}

The study was arranged as a complete block, with $3 \times 3 \mathrm{~m}$ macroplots as blocks. Each block contained Lemmon's willow and Nebraska sedge, and the 2 species were handled as treatments. Analyses were conducted using the General Linear Model (GLM) procedure in SAS (SAS 1985). The 2 years were analyzed separately. When species by sampling date interactions were significant for a variable, the data were analyzed within each sampling.date. Unless otherwise stated, statistical significance was assessed at the $p<0.05$ level.

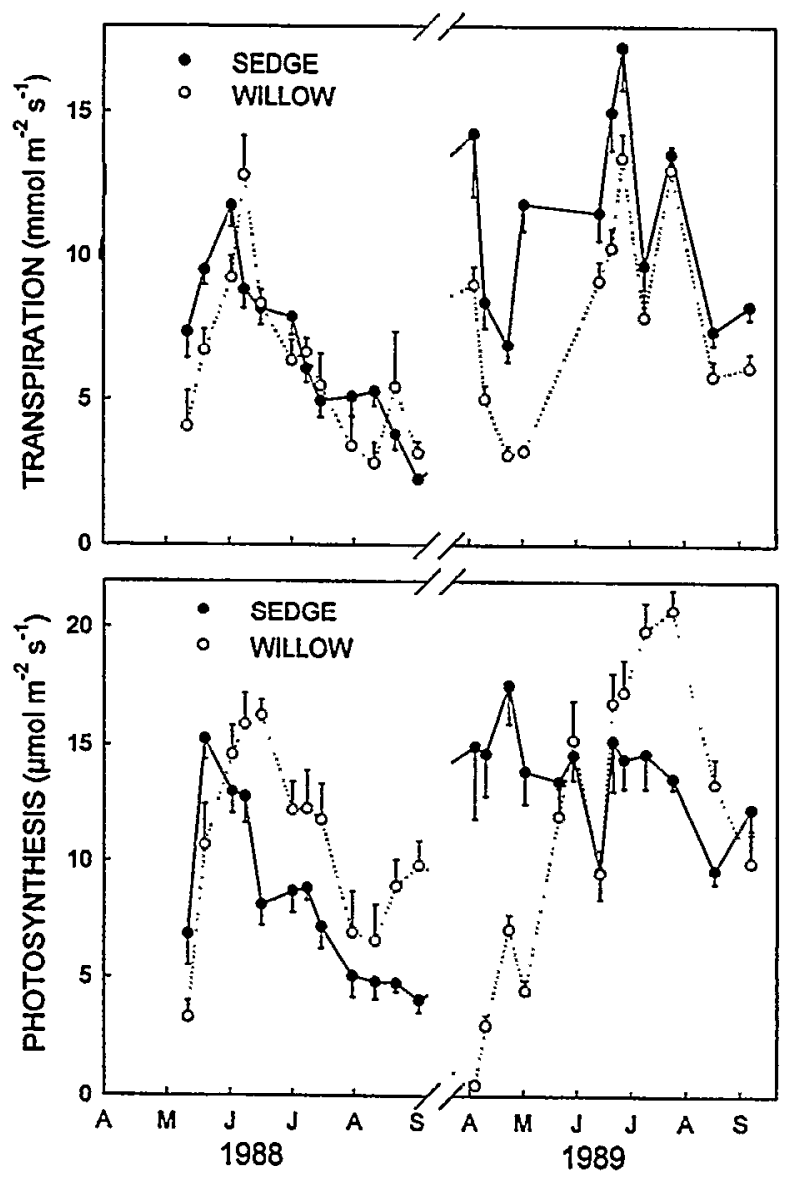

Fig. 1. Seasonal trends in photosynthesis and transpiration of Nebraska sedge and Lemmon's willow (mean \pm 1 standard error). 


\section{Results}

Seasonal trends in photosynthesis and transpiration are presented in Fig. 1. The interaction of species and date was significant $(p<0.02)$ for both parameters during each of the 2 years. Analysis of species differences at each sampling date helped explain the nature of the interactions. During 1988, photosynthesis was significantly higher for willow as compared with sedge from mid June to the end of July, and from late August through September. Differences between species were not significant in Jate May or early August. Photosyniussis was significantly lower for willow compared with sedge in the spring (April to mid-May) of 1989, significantly higher for willow during mid summer (July through August), and similar among species in September. In general, transpiration rates were similar for the 2 species during 1988 . Conversely, during the wetter 1989 , transpiration rates for sedge were significantly higher on all dates, except mid August and September.

Seasonal trends in conductance and xylem water potential are presented in Fig. 2. There were significant species by sampling date interactions for both variables. The nature of the interaction for conductance appeared to be higher values for the sedge compared to the willow during the first 4 sampling dates, and similar values during subsequent sampling dates. When the data were analyzed at each sampling date, xylem water potential was significantly different on all sampling dates, except early June 1988, and one date each in May, June, August, and September 1989. The sedge consistently had lower xylem water potential (i.e. greater stress) than did the willow. This was particularly evident during the summer of 1988.

Biomass, leaf area, and average seasonal photosynthesis values appear in Table 1. Biomass of willow is presented on a per plant basis and biomass of sedge is on a ground area basis. Willow biomass was similar each year, but during the wetter year (1989) a greater proportion of mass was allocated to leaves, and thus leaf area index was greater. Sedge biomass was greater during the average precipitation year (1989) compared to the drought year (1988). Willow maintained a higher seasonal average photosynthesis than sedge during the drought year, but the opposite was true during the average precipitation year.

Soil temperature ranged from 10 to $20^{\circ} \mathrm{C}$ (Fig. 3). Soil moisture reflected the differences in average precipitation during the 2 years. Below average precipitation in 1988 resulted in low soil water potential by early August; whereas, soil moisture remained high during the entire 1989 growing season (Fig. 3). The onset of senescence also varied by year. The initial yellowing of willow
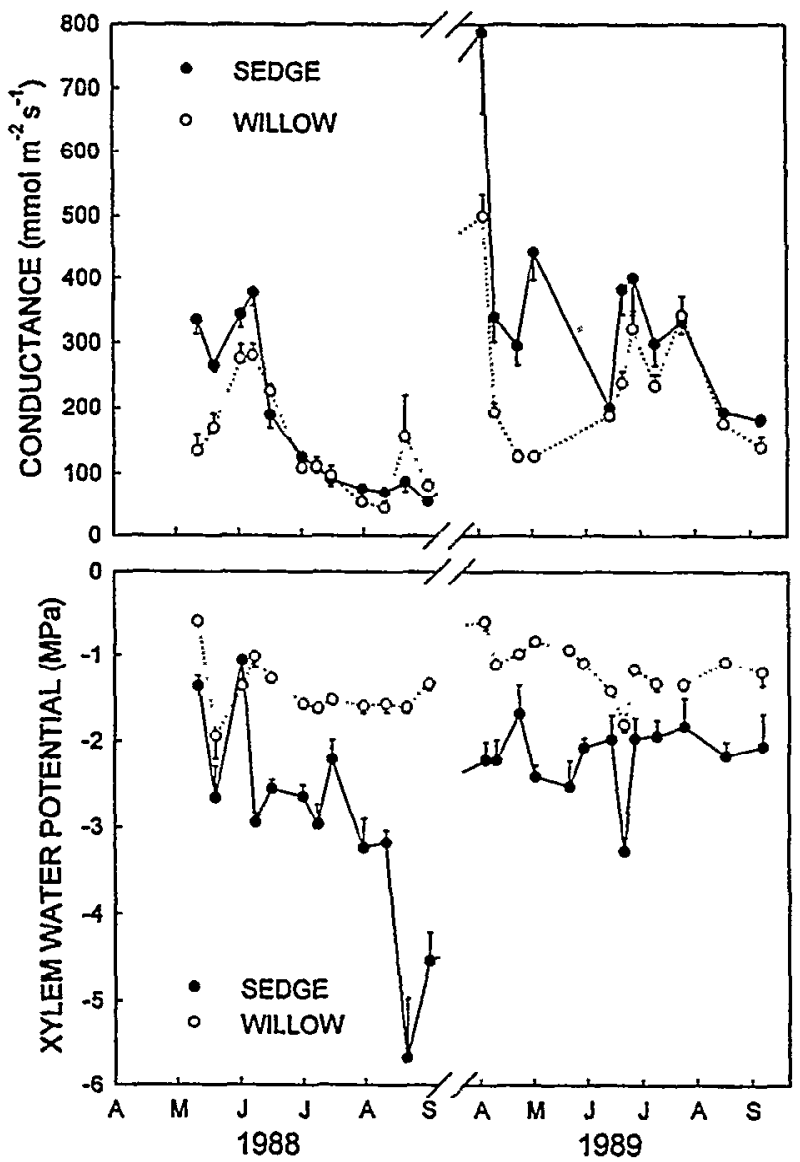

Fig. 2. Seasonal trends in xylem water potential and conductance of Nebraska sedge and Lemmon's willow (mean \pm 1 standard error).

leaves was observed on 11 August in 1988 compared to 8 September in 1989. By the first week of October, green leaves were no longer present during either year. The number of nodes with green leaves was $56 \%$ and $54 \%$ on 16 September and 28 September 1988, respectively, and 56\% on 28 September 1989.

Rooting activity of Nebraska sedge peaked in mid July for the upper 4 soil depths (Fig. 4). However, below $40 \mathrm{~cm}$ there was relatively little activity during any of the measurement dates. We observed that rooting activity was minimal in the water table. Active rooting in the upper $40 \mathrm{~cm}$ did not occur until the water table dropped below that point.

Table 1. Plant mass, leaf area, and mean seasonal photosynthesis (PS) for Lemmon's willow and Nebraska sedge. Branch number and total weight of Lemmon's willow are on a per plant basis. Percentage of branch and leaf are on a mass basis, specific leaf area (SLA) is area of leaf per unit mass, and leaf area index (LAI) is leaf area of willow projected against ground area below the willow canopy ( $n=6)$.

\begin{tabular}{|c|c|c|c|c|c|c|c|c|c|}
\hline Year & \multicolumn{7}{|c|}{ Lemmon's willow } & \multicolumn{2}{|c|}{ Nebraska sedge } \\
\hline & & (kg/plant) & $(\%)$ & $(\%)$ & $\left(\mathrm{cm}^{2} / \mathrm{g}\right)$ & $(\mu$ mole & second $\left.^{-1}\right)$ & $\left(\mathrm{g} / \mathrm{m}^{2}\right)$ & $\left(\mu\right.$ moles $\mathrm{m}^{-2}$ second $\left.{ }^{-1}\right)$ \\
\hline 1989 & $42.2 \pm 4.6$ & $6.2 \pm 2.7$ & 82.0 & 18.0 & $81.0 \pm 7.3$ & 5.1 & 11.5 & $202.5 \pm 28.2$ & 13.7 \\
\hline
\end{tabular}

Mean \pm standard deviation 


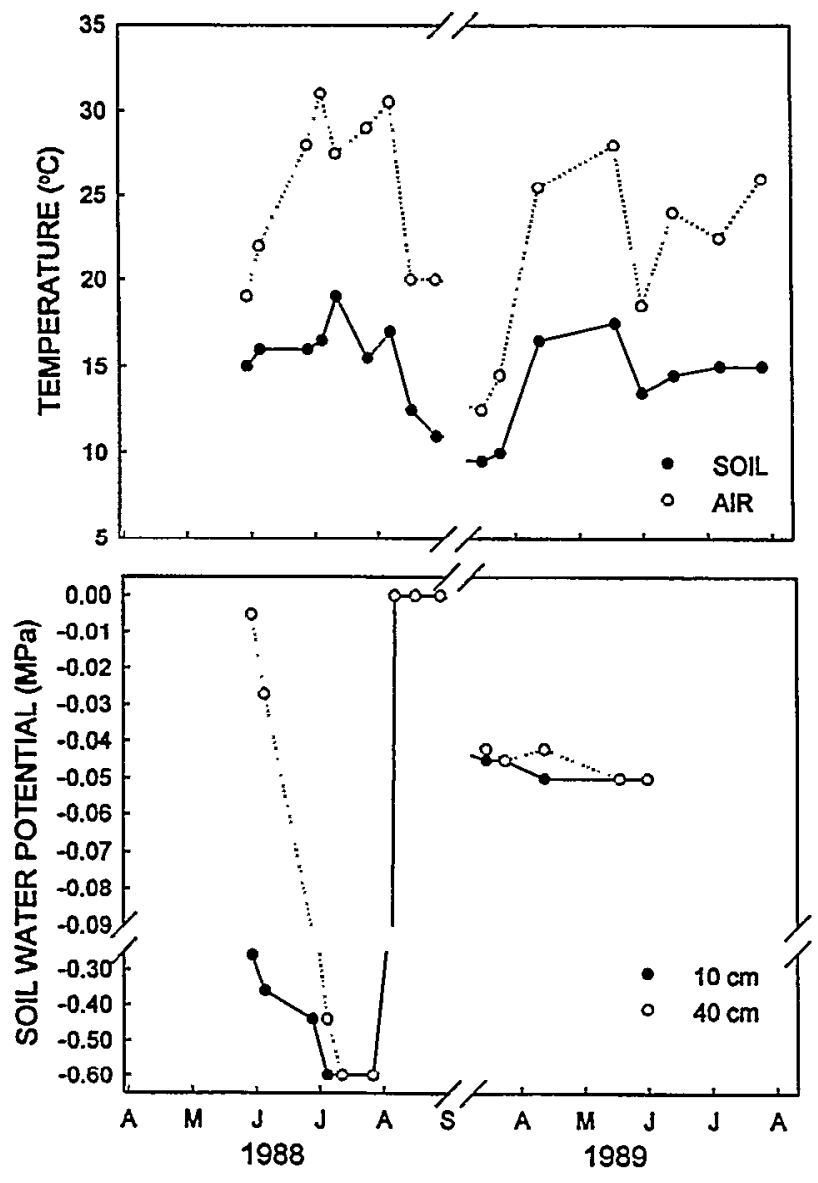

Fig. 3. Midday soil water potential, soil temperature and air temperature for the study area on Freeman Creek near Portola, Calif.

\section{Discussion}

The 2 species studied have different growth forms and thus differences in physiological response might also be expected. The seasonal pattern of photosynthesis did vary between species. Lemmon's willow leaves did not reach maximum photosynthetic values until mid-summer (Fig. 1). During 1989 the leaves were 1 to $2 \mathrm{~cm}$ long when we initiated measurements and averaged 4.4 $\mathrm{cm}$ by 13 June when photosynthesis increased to more than $10^{\circ}$ ( $\mu$ moles $\mathrm{m}^{-2}$ second $\mathrm{d}^{-1}$ ). Thus, there would appear to be sufficient leaf material early in the season for Lemmon's willow to achieve reasonably high photosynthesis. Conductance was sufficient (Fig. 2) during this period such that stomatal closure did not appear to limit photosynthesis of willow during the early growth phase. Midday soil and air temperatures (Fig 3.) during the study did not appear low enough to limit photosynthesis. Anderson and McNaughton (1973) found that transpiration and photosynthesis of several willow species were not affected when soil temperature was reduced from $20^{\circ} \mathrm{C}$ to $3^{\circ} \mathrm{C}$. In the present study, soil temperature was well above $3^{\circ} \mathrm{C}$ during all measurement dates.

Nebraska sedge maintained higher photosynthesis than Lemmon's willow early in the growing season, but had lower photosynthesis during the latter part of the season. The 2 species also exhibited very different yearly responses. During the drought year (1988), Lemmon's willow maintained higher seasonal average photosynthesis than Nebraska sedge, whereas the opposite ranking occurred during the average year (Table 1). The explanation presumably lies in the rooting habits of the 2 species. Nebraska sedge tends to concentrate rooting activity in the upper $40 \mathrm{~cm}$ of the soil profile (Fig. 4, Manning et al. 1989), whereas, willows are able to use groundwater (Busch et al. 1992). Thus, during drought years when surface soil moisture was limiting (Fig. 4), the sedge would be at a disadvantage compared with willows. Over the 2-year period, mean photosynthetic rates for the 2 species were remarkably similar ( 10.9 and $11.1 \mu$ moles $\mathrm{m}^{2} \mathrm{sec}$ ond $^{-1}$ for Nebraska sedge and Lemmon's willow, respectively). Although the mean photosynthetic rate was similar, the seasonal and yearly patterns of photosynthesis were very different between species.

Probably the most striking difference between the 2 species was in xylem water potential. Lemmon's willow had less negative values of xylem water potential than Nebraska sedge during all measurement dates and did not exhibit the seasonal trend evident in Nebraska sedge during the drought year. When averaged over the season, Nebraska sedge has xylem water potential values that were twice as negative (-3.0 and $-2.2 \mathrm{MPa}$ for 1988 and 1989 , respectively) as those of Lemmon's willow (-1.4 and -1.1 MPa for 1988 and 1989, respectively). Young et al. (1985) measured xylem water potential for several species of Salix in Wyoming and also found minimum values in the range of -1.0 to $-2.0 \mathrm{MPa}$. In contrast, transpiration and conductance were similar for the 2 species, except that Nebraska sedge tended to have higher early season values compared with Lemmon's willow. Thus, Lemmon's willow maintained water flow to leaves and exhibited less "water stress" (as inferred from xylem water potential) than Nebraska sedge.

Many of the seasonal differences in water relations between the 2 species can probably be explained by belowground structures. Nebraska sedge has a very profuse rooting habit with about $99 \%$ of the root length in small $(<1 \mathrm{~mm})$ roots (Manning et al. 1989). We could not find any detailed root observations for willows; however, woody species tend to have a larger proportion of roots

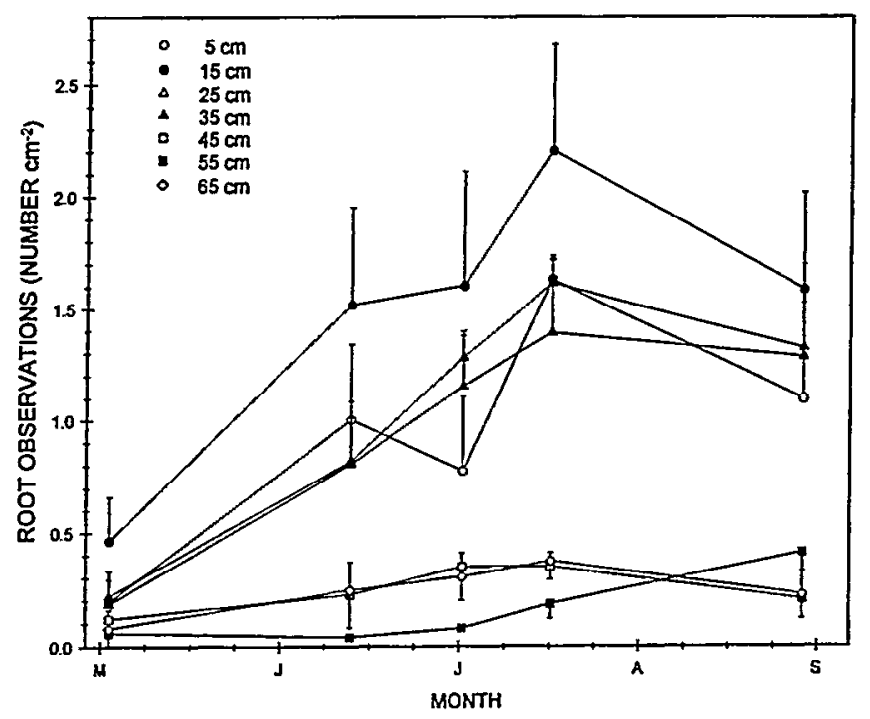

Fig. 4. Seasonal trend in rooting activity of Nebraska sedge during 1989 (mean \pm standard error, $n=3$ ). 
in the $>1 \mathrm{~mm}$ size classes. Strong and LaRoi (1983) found that only $5 \%$ of the root mass of aspen was in the $<2 \mathrm{~mm}$ size class. In general, the fibrous root system of Nebraska sedge should be efficient at extracting moisture from the upper portions of the soil profile. On the other hand, the large diameter woody roots of Lemmon's willow should be more efficient than Nebraska sedge at transporting water from the water table to transpiring leaves.

It appears that Nebraska sedge concentrates roots in the upper soil profile as evidenced by rooting activity (Fig. 4) and previously published data on root biomass and root length density (Manning et al. 1989). In a Nebraska sedge community, Manning et al. (1989) found that $85 \%$ of the root length between $0-40 \mathrm{~cm}$ was concentrated in the upper $20 \mathrm{~cm}$ of the soil profile. We found the greatest number of active roots at $15 \mathrm{~cm}$ with little rooting activity below $40 \mathrm{~cm}$. We also noted that active root growth did not occur directly in the water table. Root growth occurred at depths above the water table. Kawase (1981) cited decreased root growth as one of the responses plants typically exhibit during waterlogged conditions. The mid-summer peak for rooting activity suggests riparian species may be out-of-phase with upland sagebrush steppe communities in timing of root growth. In general, rooting activity of perennial upland species peaks in late spring or early summer when soil water is available (Richards 1984, Harris 1977, Fernandez and Caldwell 1975). Riparian graminoid species may have delayed root growth until soils are not saturated or the water table recedes.

Peak standing biomass of willow was similar during the 2 year period, however, a greater proportion of biomass was allocated to leaves during the average precipitation year compared to the dry year (Table 1). The greater allocation to leaves explains the higher leaf area index of willow during 1989 compared to 1988 . We did not measure leaf area index of sedge, but the higher biomass (which is almost entirely leaf material) suggests leaf area index was also higher in 1989 as compared with 1988. The decrease in leaf area of Lemmon's willow and biomass of Nebraska sedge in the dry vs. average precipitation year was very similar (24\% and $25 \%$, respectively). However, as previously mentioned, the seasonal photosynthesis of Nebraska sedge was reduced to a greater extent by drought than that of Lemmon's willow ( $41 \%$ and $6 \%$ reduction, respectively).

Seasonal differences between Lemmon's willow and Nebraska sedge existed for photosynthesis, transpiration, conductance, and xylem water potential. These trends could be explained by yearly changes in precipitation, and by morphological and physiological differences between the 2 species. The willow achieved greater maximum photosynthesis than the sedge during both dry and normal years, while it maintained similar or slightly lower rates of transpiration and conductance. However, average photosynthetic rate over the 2 year study period was very similar between species. Similar rates of transpiration between the 2 species, yet higher (less negative) xylem water potential for the willow suggest that willow had lower resistance to water movement than sedge. During the year of below average precipitation, willow had a higher than average photosynthesis throughout the growing season. The ability of willow to tap the water table may explain its ability to maintain photosynthesis during summer drought.

\section{Literature Cited}

Anderson, J.E. ,and S.J. McNaughton. 1973. Effects of low soil temperature on transpiration, photosynthesis, leaf relative water content, and growth among elevationally diverse plant populations. Ecology 54:1220-1233.

Busch, D.E., N.L. Ingraham, and S.D. Smith. 1992. Water uptake of woody riparian phreatophytes of the southwestern United States: a stable isotope study. Ecol. Appl. 2:450-459.

Fernandez, O.A., and M.M. Caldwell. 1975. Phenology and dynamics of root growth of three cool semi-desert shrubs under field conditions. J. Ecology 63:703-714.

Harris, G.A. 1977. Root phenology as a factor of competition among grasses. J. Range Manage. 30:172-177.

Hickman, J.C. 1993. The Jepson manual: higher plants of California. University of California Press, Berkeley, Calif.

Karl, M.G., and P.S. Doescher. 1991. Monitoring roots of grazed rangeland vegetation with the root periscope/mini-rhizotron technique. J. Range Mange. 44:296-298.

Kawase, M. 1981. Anatomical and morphological adaptation of plants to waterlogging. Hort. Sci. 16:30-34.

Kovalchik, B.L. 1987. Riparian zone associations: Deschutes, Ochoco, Fremont, and Winema National Forests. USDA Forest Service. Region 6 Ecology Tech. Paper 279-287.

Manning, M.E., S.R. Swanson, T. Svejcar, and J. Trent. 1989. Rooting characteristics of four intermountain meadow community types. J. Range Manage. 42:309-312.

Richards, J.A. 1984. Root growth response to defoliation in two Agropyron bunchgrass: field observations with an improved root periscope. Oecologia 64:21-25.

Strong, W.L., and G.H. LaRoi. 1983. Root-system morphology of common boreal forest trees in Alberta, Canada. Can. J. For. Res. 13:11641173.

Young, D.R., I.C. Burke, and D.H. Knight. 1985. Water relations of high-elevation phreatophytes in Wyoming. Amer. Midl. Natr. 114:384392.

Youngblood, A.P., W.G. Padgett, and A.H. Wilson. 1985. Riparian type classification of eastern Idaho-western Wyoming. USDA Forest Service, Region 4, R4-Ecol-85-01. 